
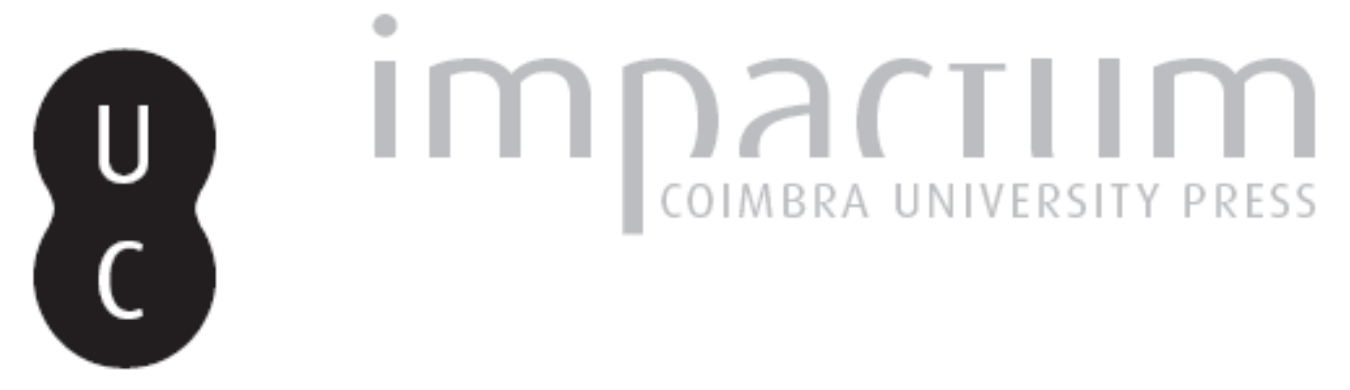

\title{
Arte: o fazer como forma de conhecimento
}

\section{Autor(es): Olaio, António}

Publicado por: Editorial do Departamento de Arquitectura

URL persistente:

URI:http://hdl.handle.net/10316.2/37484

DOI:

DOI:http://dx.doi.org/10.14195/0874-6168_5_4

Accessed : $\quad$ 26-Apr-2023 12:09:11

A navegação consulta e descarregamento dos títulos inseridos nas Bibliotecas Digitais UC Digitalis, UC Pombalina e UC Impactum, pressupõem a aceitação plena e sem reservas dos Termos e Condições de Uso destas Bibliotecas Digitais, disponíveis em https://digitalis.uc.pt/pt-pt/termos.

Conforme exposto nos referidos Termos e Condições de Uso, o descarregamento de títulos de acesso restrito requer uma licença válida de autorização devendo o utilizador aceder ao(s) documento(s) a partir de um endereço de IP da instituição detentora da supramencionada licença.

Ao utilizador é apenas permitido o descarregamento para uso pessoal, pelo que o emprego do(s) título(s) descarregado(s) para outro fim, designadamente comercial, carece de autorização do respetivo autor ou editor da obra.

Na medida em que todas as obras da UC Digitalis se encontram protegidas pelo Código do Direito de Autor e Direitos Conexos e demais legislação aplicável, toda a cópia, parcial ou total, deste documento, nos casos em que é legalmente admitida, deverá conter ou fazer-se acompanhar por este aviso.

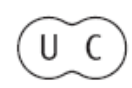




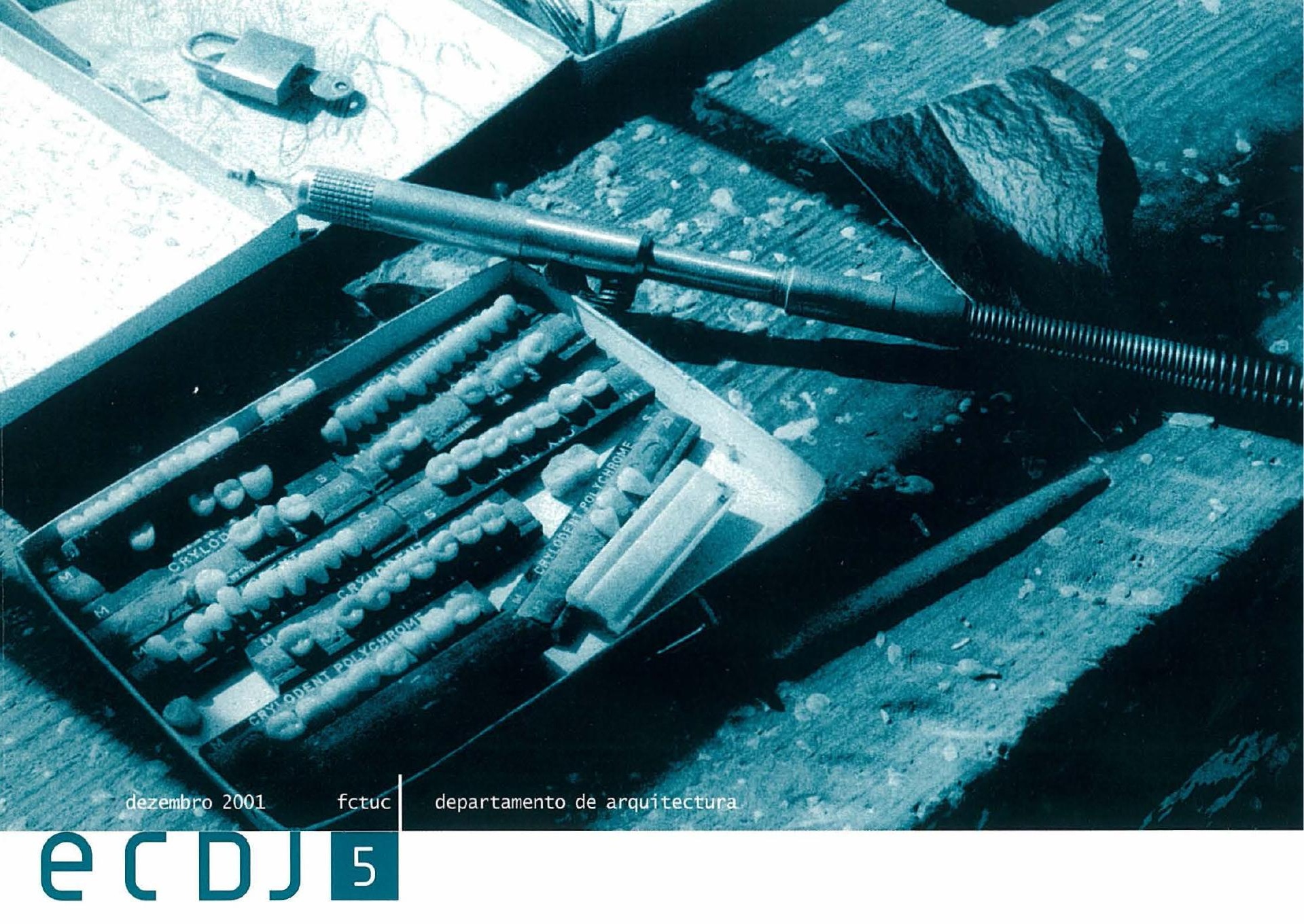

\section{investigação em arquitectura [?]}

George Teyssot

Paulo Providência | Mário Krüger | Wałter Rossa | António olaio

Outra abertura adelino gonçałves

Sti11Life, duração e abandono na obra de john hejduk francisco ferreira

Onde há fogo, nós levamos gasolina pedro bandeira

Apontamentos sobre a arquitectura religiosa do séc. XX em Portugal cidália silva

o desafio ecológico luís pinto faria

Pescada de rabo na boca patrícia miguel carvalho

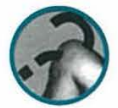


texto antónio olaio

Arte: o Fazer como Forma de
Conhecimento 


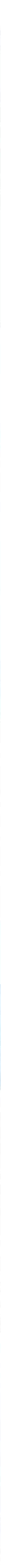


> É bastante engraçado o facto de Duchamp, sendo frequentemente associado ao afastamento da ideia de arte enquanto manufactura, ter definido arte enquanto fazer e fazer quase que com as mãos.

> Duchamp, com a definição de arte enquanto fazer, nesta aparente redução da ideia de arte ao artefacto, numa atitude que poderá aparentar ser um gesto de puro niilismo, de pura dessacralização e banalização da arte, mais não estará do que situar a arte ao nível, na família, dos artifícios (da ponta de sílex ao supermercado?).

Duchamp, aqui, mais uma vez revela a sua estratégia de reflexão sobre arte, no sentido da melhor forma, da forma mais límpida de abordar a arte, que é parecer que não se The dá grande importância. No sentido de uma indiferença, ou melhor de uma indiferenciação da arte em relação a todas as coisas.

> 0 facto da arte poder ser, assim, encarada como artefacto, como uma cadeira ou um copo, gera uma forma de abordagem que pode ser extremamente significante.

> Desta forma, na relação entre a concepção de um objecto e a sua manufactura, poderemos considerar um crescente grau de sofisticação na forma como os conceitos se relacionam com o objecto produzido. Desde a satisfação de uma função primária, a um grau de sofisticação tal que a própria ideia de função se complexifica ao ponto de, como nas obras de arte, parecer não servir para nada. 

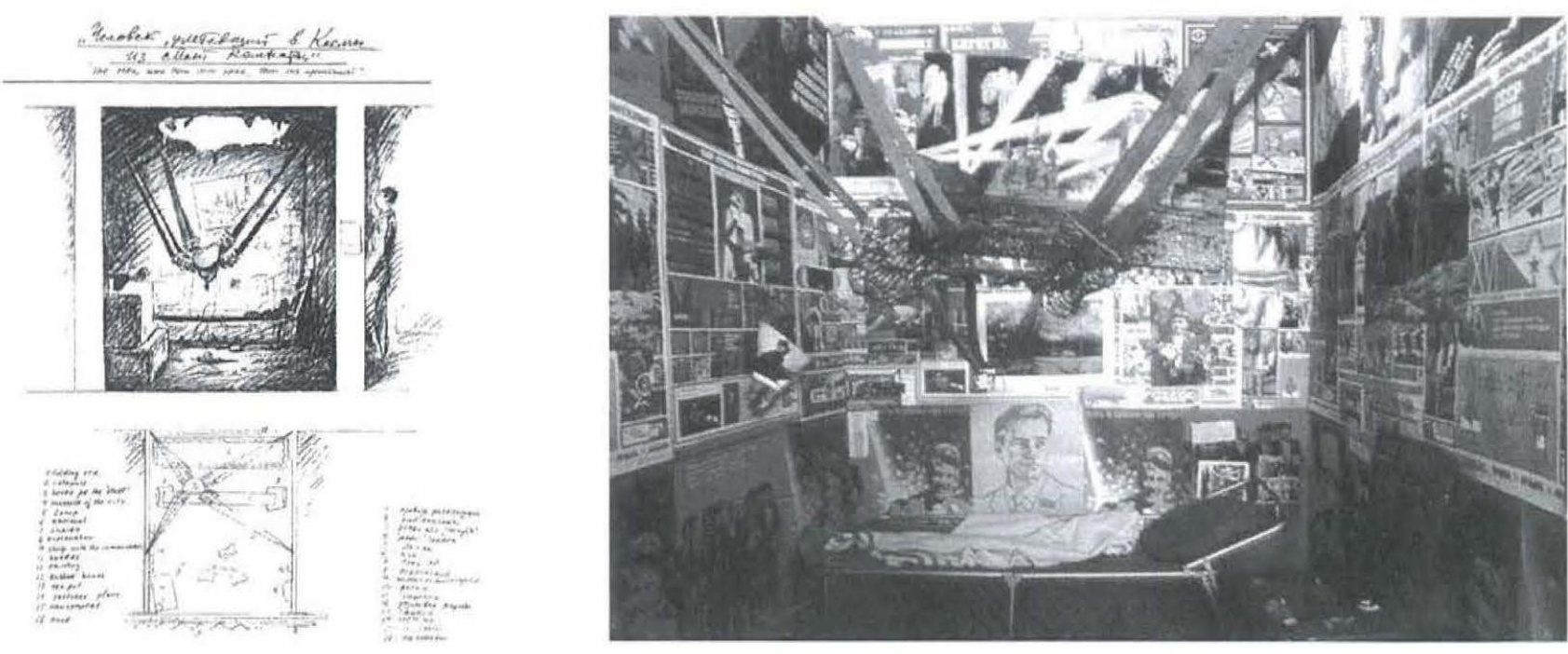

> Mas, de facto, mesmo a própria sobrevivência não depende só da satisfação das necessidades primárias.

> E a arte é imagem de uma forma mais complexa da ideia de necessidade.

> Esta definição de arte enquanto meramente fazer, pela sua extrema simplicidade, parece ter a intenção de afastar a arte das concepções mais obscuras e, quantas vezes essas concepçőes poderão ser intencionalmente obscuras, como se a arte fosse uma espécie de mistério insondáve1.

> Na relação da arte com a inteligência, este encarar da arte como algo de obscuro, se, por um lado, pode induzir a concepções de exaltação romântica, também, para conforto de uma sociedade dominada pela racionalidade mais linear, pode levar a encarar os artistas como aqueles que não pensam, na exaltação do que chamam sentimento. E a ideia tão popular de génio criador mais parece ser sinónimo de aquele que faz sem pensar, celebrando-se muitas vezes a intuição artística como se a intuição fosse fruto de seres que satisfariam uma ideia estupidamente nostálgica do ser primitivo, como se o artista fosse uma espécie de bom selvagem (ainda me 1embro dos tão celebrados Novos Selvagens nos anos 80 , onde a apreciação da sua obra sublinhava, da forma mais redutora, um regresso à pintura, como se a pintura tratasse de tintas e, sobretudo, se as pinceladas fossem largas e evidentes, numa ideia de expressionismo que mais não seria, no simplismo do discurso de então de alguns críticos de arte, do que uma mimesis de uma certa imagem de expressão). 
> De facto, o que chamamos intuição, mais não será que um pensamento mais rápido e complexo, tão rápido e complexo que não é sequer perceptíve1 pela lenta racionalidade.

> os processos da intuição são tão ágeis que, que quando a racionalidade os procura entender, eles já aconteceram.

Terá talvez sido este pensamento complexo e ágil que permitiu a Einstein a criação da teoria da relatividade que, certamente, não teria sido possíve1 meramente nos mecanismos de uma estrita racionalidade. Será certamente a intuição um dos principais motores do conhecimento, isto porque somos bem mais inteligentes do que somos.

> 0 aparente disparate do final da frase anterior, deixará eventualmente de o parecer se considerarmos os mecanismos em jogo no ensino das artes.

Grande parte da actividade de ensinar arte não será, propriamente, e em rigor, ensinar.

> Parece-me ser, pela relação que tenho com os alunos nas aulas das disciplinas de desenho deste curso de arquitectura, sobretudo nos aspectos do desenho que se situam para além da representação, principalmente revelar e desenvolver aspectos menos exercitados das suas capacidades intelectuais.

> A actividade artística, e considero a resposta a exercícios das disciplinas de desenho uma manifestação da prática artística, é uma forma de revelar aspectos da percepção e conhecimento do mundo que, infelizmente, muitas vezes é recalcada por uma racionalidade dominadora. E distingo aqui racionalidade de razão, usando a palavra racionalidade para denominar esta espécie de doença que nos faz tomar por um verdadeiro conhecimento a utilitária e pragmática simplificação da realidade de que muitas vezes a razão se serve para ser operativa.

> E a confusão chega ao cúmulo de confundirmos a complexidade da realidade com esta redução a uma linearidade utilitarista, como se pretendêssemos substituir o espaço, nem sequer por um plano, conformando-nos a substituí-1o por uma Tinha.

Pois, quanto mais Tinear mais Tivre estaria de qualquer ambiguidade.

o que é um terrível disparate! o que é, de facto, um facto é que a objectividade é a coisa mais ambígua que há. 
> Isto ao ponto de dar o nome de objectividade aos pensamentos mais Tineares.

$>$ E quanto mais linear, mais objectivo seria o pensamento.

$>$ Pois, quanto mais Tinear mais livre estaria de qualquer ambiguidade.

> o que é um terrível disparate!

$>$ o que é, de facto, um facto é que a objectividade é a coisa mais ambigua que há.

> Bem mais ambígua que a subjectividade, enquanto subjectividade que percepciona, que fiłtra, pela dinâmica da percepção, a objectividade, e a conforma aos dados empíricos do sujeito e, fatalmente, ao conhecimento de uma linguagem que a procura traduzir (e não sei se pensar em português é o mesmo que pensar em alemão, mas suspeito que devem haver algumas diferenças: certamente, a Torre de Babel ainda terá vindo complicar mais as coisas).

> Se conseguíssemos conceber a objectividade pura, certamente deparariamos com a ambiguidade na sua manifestação absoluta. Mas, de facto, como só conhecemos o mundo conforme o vemos, a única objectividade a que poderemos aceder é a nossa subjectividade, quando a subjectividade é usada para percepcionar a subjectividade.

> ou melhor, por outras palavras, quando a subjectividade é o objecto de percepção.

> Assim, esta única verdadeira forma de aceder a uma objectividade não passará de um puro acto de introspecção.

> Quando (dado o contexto desta revista) um arquitecto reflecte sobre uma cidade, reflecte sobretudo sobre as relações dos dados que o seu cérebro possui com a percepçăo que tem sobre a cidade, estando aqui perante, ao mesmo tempo, um acto filosófico (mesmo quando a filosofia tem o fazer como finalidade) e um acto introspectivo.

> Sendo eu artista plástico e professor de desenho no curso de arquitectura da universidade de coimbra, encaro as duas actividades como sendo indissociáveis.

> Tanto o que faço como artista quanto os exercícios que proponho aos alunos (sobretudo no $2^{\circ}$ ano, onde os rudimentos instrumentais já deverão estar dominados) encaro como parte de uma investigação, pois encaro a função de artista plástica como algo que não se esgota na autoria de obras de arte, sendo estas sobretudo concretizações, ou mesmo, resíduos de toda uma relação com a fruição estética. 
> Não foi só pela procura de um desenvolvimento instrumental que, no último ano lectivo, propus como exercício de desenho aos alunos do $2^{\circ}$ ano trabalhos que partiam dos desenhos de representação do esqueleto que eles tinham feito, para a criação de novas composiçōes.

> A partir da estrutura do esqueleto humano, os alunos, passando por fases de estilização onde anulavam a acidentalidade da caligrafia, criavam composiçöes onde as metamorfoses que o desenho original sofria eram motivadas por uma relação com o suporte (na ideia de inter-relação que compõe o conceito de composição).

\section{Passando por fases de esti lização onde anulavam a acidentalidade da caligrafía, criavam composições onde as metamorfoses que o desenho original sofria eram motivadas por uma relação com o suporte.}

> Mas não foi a pura atitude formalista que conduziu os processos de composição, porque a ideia de esqueleto estava sempre presente, na plena ambiguidade de sugerir múttiplas ideias, como: estrutura, corpo, indivíduo, construção, materią de construção, montagem, desmontagem, remontagem, Tego.

> Perante a surpresa agradáve1 dos trabalhos que surgiram decidimos fazer uma exposição, ou methor os trabalhos decidiram por nós, nós năo fizemos mais do que Thes obedecer.

> E, como síntese das relações que os desenhos sugeriam, chamámos à exposição: A capela dos ossos, ou se os ossos fossem lego.

> Capela, pela relação destes ossos metamorfoseados com a ideia de edificação, lego pela noçẫo aqui provada da arte como campo de possibilidades.

> De facto, a criatividade em arte, e a arte acontece quando um objecto ultrapassa a sua objectualidade (mesmo quando a objectualidade é um dos ingredientes de uma obra de arte) para a gestaçáo de um espaço, de um campo de possibilidades.
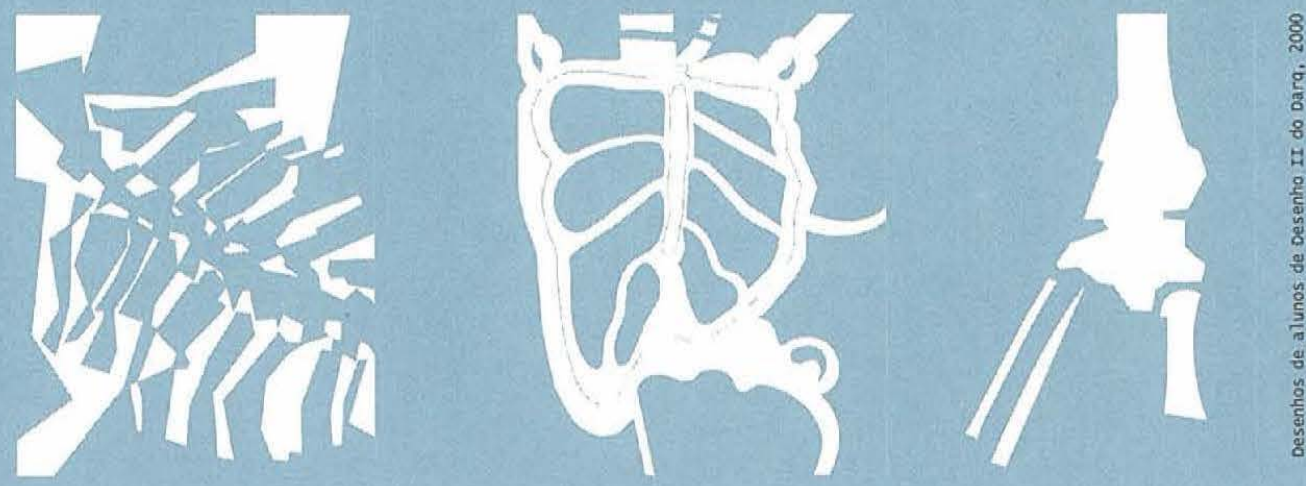

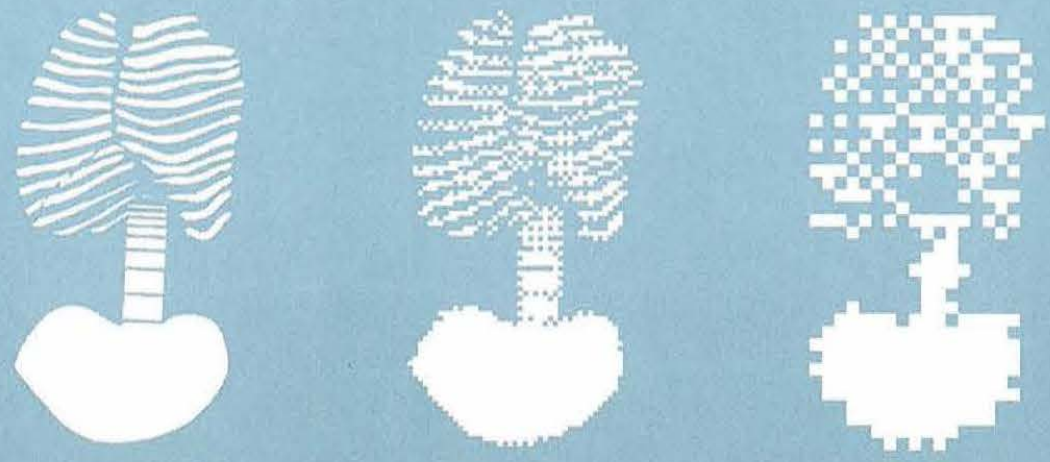

> Quando Ilya Kabakov cria o homem que voou para o espaço do seu apartamento cria uma instalação que simula a possibilidade de, com os meios mais rudimentares, e tendo-se a si próprio e ao seu quarto, ao seu espaço mais infimo, um homem conseguir conquistar o espaço.

> Para além da força que as viagens espaciais teriam no imaginário soviético, Kabakov, aqui, parece sublinhar a ideia de arte como processo de concepçăo, mesmo na rudimentaridade dos meios físicos (näo propriamente na rudimentaridade dos meios mentais), de abertura de um campo de possibilidades.

> De um quartinho para o Espaço, ou melhor da relação entre a inteligência do artista e os elementos do seu espaço, mesmo que infimo, para a sua ampliação para um campo de infinitas possibilidades, tão vasto que nem sequer a ideia de dimensão fará sentido (e nem mesmo a ideia de vasto).

> Por outro 7ado, Anthony Gormley cria esculturas/corpos ou, melhor, esculturas que parecem ser representaçäo de moldes de um corpo. De um corpo sem identidade, na maximização da seu sentido simbólico.

\section{como se o espaço de vida de um indivíduo nầ fosse} mais do que o espaço dado pelos timites do seu corpo.

- Os corpos/moldes das esculturas de Antony Gormley parecem confinar a existência do indivíduo ao espaço mais ínfimo, como se o espaço de vida de um individuo não fosse mais do que o espaço dado pelos limites do seu corpo.

- Mas em Gormley um corpo é encarado também pelo seu carácter de representação. um corpo representando um individuo.

E. aqui, na relaçäo de um indivíduo com o mundo, o corpo poderá ser representação deste espaço concentracionário que reside na condiçăo de se ser um individuo.

Encarando o corpo como representação da ideia de indivíduo e, nessa condiçăo, sendo os seus ossos lego, um individuo é imagem de todas as construçōes possiveis. e [ B J 